\title{
Desvendando as Geociências: alfabetização científica em oficinas didáticas para 0 ensino fundamental em Porto Velho, Rondônia
}

\author{
UNRAVELING THE GEOSCIENCES: SCIENTIFIC LITERACY THROUGH EDUCATIONAL WORKSHOPS FOR TEACHING \\ elementary school students at Porto Velho, Rondônia \\ Cassiana Purcino Perez ${ }^{1}$, Luana Cardoso de Andrade ${ }^{1,2}$,Morgania Ferreira Rodrigues ${ }^{1}$. \\ 1-Scientia Consultoria Científica Ltda., Rua Armando D'Almeida, 52, Butantã, São Paulo, SP \\ 2- Grupo de Pesquisa Geociências, Universidade Federal de Rondônia, Campus José Ribeiro Filho.
}

\section{Manuscrito: \\ Recebido: 20/5/2013 \\ Corrigido: 16/6/2014 \\ Aceito: 9/10/2014}

Citation: Perez C.P., Andrade L.C. ,Rodrigues M.F. 2015. Desvendando as Geociências: a alfabetização científica por meio de oficinas didáticas para alunos do ensino fundamental em porto velho, Rondônia. Terræ Didatica, 11(1):42-51. <http:// www. ige.unicamp.br/terraedidatica/>.

Keywords: Geosciences, Paleontology, workshops, educational games, Scientific Literacy.
ABSTRACT: Geosciences are essential for understanding the physical world, but they are still not used frequently to promote Scientific Literacy (SL) Basic Education in Brazil. This study investigated the effectiveness of didactic workshops to teach $\mathrm{Ge}$ osciences, and examined their contribution to the process of SL of Elementary school students in Porto Vellho, Rondonia,". Each of the nine workshops was applied in two 5th grade classes, using different teaching tools and addressing a specific theme of Geosciences with emphasis in Paleontology. To evaluate the effectiveness of this method, we performed knowledge tests before and after the project, comparing them in qualitative and quantitative analyses. Based on the results, we found: 1) basic comprehension of specific terms; 2) comprehension of the steps required to identify and study fossils; 3 ) understanding of the steps required for the fossilization process; 4) understanding of the nature of science and scientific work; 5) recognition of the importance of disseminating scientific knowledge to society. The results highlight the feasibility of beginning SL during the first years of school life, and the relevance of Geosciences as a means to engage students in scientific themes.

\section{Introdução}

Desde a década de 1950, diversos trabalhos de pesquisa em ensino de ciências vêm discutindo a possibilidade de aulas que permitam o início do processo de Alfabetização Científica (AC) já nos primeiros anos da vida escolar (Hurd 1958, Lorenzetti e Delizoicov 2001, Sasseron e Carvalho 2008, Furman 2009). No entanto, as implicações do tema no ensino formal das ciências apresentam diferentes propostas quanto aos conhecimentos, competências, capacidades, atitudes e valores necessários a qualquer indivíduo, numa sociedade caracterizada pelo crescente impacto da ciência e da tecnologia (Chagas 2000).

Apesar de numerosas e diversificadas, essas propostas apresentam aspectos em comum que se relacionam, principalmente, a visão da importância de formar alunos capazes de compreender seu mundo de forma crítica, numa perspectiva de elaboração de conceitos científicos mais coerentes e relevantes para a vida diária (Lorenzetti e Delizoicov 2001, Penha, Carvalho e Vianna 2009, Sasseron e Carvalho 2008). Lira eTeixeira (2011, p. 3) sintetizam esse consenso ao afirmarem:

\footnotetext{
As aulas de ciências devem possibilitar ao aluno a problematização e investigação de fenômenos vinculados ao seu cotidiano, para que esse seja capaz de dominar e usar os conhecimentos construídos nas diferentes esferas de sua vida, buscando benefícios práticos para as pessoas, a sociedade e o meio-ambiente.
}

Outro consenso que parece emergir das diferentes propostas para o processo de AC refere-se à necessidade de permitir que os alunos trabalhem ativamente na construção de seu conhecimento desde o início da escolarização (Sasseron e Carvalho 2008), mesmo antes que a criança saiba ler e 
escrever (Lorenzetti e Delizoicov 2001). De acordo com Bacci, Oliveira e Pommer (2009), é nessa fase do desenvolvimento infantil que a curiosidade sobre o mundo que rodeia as crianças está mais aguçada e elas revelam grande desenvoltura quando observam e questionam fenômenos do dia-a-dia. Aos educadores, cabe utilizar esse desejo natural de conhecer o mundo como plataforma sobre a qual possam construir ferramentas de pensamento que permitam aos estudantes compreender como as coisas funcionam e pensar por eles mesmos, ou, como diz Furman (2009), "educar" a curiosidade.

Utilizando os questionamentos das crianças sobre o mundo que as rodeia como ponto de partida é possível (e desejável) estimulá-las a explorar, a fazer observações e comparações, a levantar hipóteses, a buscar fontes de informações, a descobrir padrões e exceções, a testar suas respostas, reelaborando seu conhecimento, como fazem os cientistas. Ao trabalhar o desenvolvimento de métodos de investigação, na busca de respostas para suas próprias questões desde os primeiros anos da educação formal, possibilita-se que as crianças encarem a ciência como ela realmente é: não uma série de conceitos fechados que devem ser decorados, mas uma atividade humana, dinâmica e constantemente em construção.

Nesse sentido, os temas relacionados especificamente às Geociências ou Ciências da Terra, têm despertado cada vez mais interesse entre os estudantes das séries iniciais (Bacci, Oliveira e Pommer 2009), especialmente, por tratarem de questões sobre o funcionamento do planeta em que vivemos e sua evolução ao longo do tempo. O entendimento da evolução geológica do planeta desde a escola básica culmina em uma compreensão do sistema Terra por completo (Carneiro, Toledo e Almeida 2004). As Geociências, constituindo-se também em uma ciência experimental, utilizam amplamente os métodos comuns às outras ciências (Carneiro, Toledo e Almeida 2004), construindo, na prática, métodos de investigação e aguçando a curiosidade do aluno pelos caminhos do saber científico.

A Paleontologia, especificamente, é inserida nos Parâmetros Curriculares Nacionais (PCN) das Ciências Naturais para o Ensino Fundamental (Brasil 1998) tanto no eixo temático "Terra e Universo" quanto no eixo temático "Vida e Ambiente" (neste como conhecimento necessário para se compreender as informações e os conceitos da Ecologia), mas ainda não é adequadamente explorada. De acordo com os PCN, a interpretação de registros concretos do passado (os fósseis) pode facilitar não só a compreensão do significado do tempo geológico, não cíclico, como ainda a compreensão do processo de evolução da vida, por meio da comparação entre espécies extintas e atuais. Segundo Mello, Mello e Torello (2005), as principais dificuldades para o ensino dessa ciência são a deficiência de material didático ${ }^{1}$ e paradidático ${ }^{2}$ e a deficiência na formação de professores/educadores sob o mito da complexidade, pois para muitos o assunto é tido como um tema "muito complexo". Devido a isso, ainda há a carência de abordagem da temática geocientífica no nível fundamental do ensino (Piranha e Carneiro 2009).

Uma alternativa para reverter tal situação é construir junto com os alunos a noção do que é fazer ciência, colaborando para o aprimoramento da estratégia de ensino por meio de oficinas didáticas com temas geocientíficos. Discutir conceitos de Geociências significa tornar visíveis os sinais da natureza (Mesquita et al. 2011) e, por meio das oficinas didáticas, é possível trabalhar uma série de instrumentos, que buscam envolver o aluno e facilitar a compreensão dos temas, mostrando a eles os sinais da natureza que muitas vezes são considerados complexos, mas estão incorporados ao seu cotidiano através de diferentes meios de comunicação.

As oficinas didáticas facilitam ainda a interação entre mediador e aluno, tornando as trocas de experiências mais fáceis. Auxiliam também no maior contato com o tema em questão, pois se utilizam de ferramentas que aproximam o aluno do objeto de estudo, tanto no Ensino Fundamental como no Ensino Infantil, como defendido por Mello, Mello e Torello (2005, p. 400):

\section{No momento em que a criança está em contato com o objeto de investigação, é sabido que sua capacidade de absorção dos conhecimentos é muito grande $[\ldots]$ sendo importante que todo e qualquer conhecimento ao alcance das crianças da Educação Infantil, que chame atenção, seja transmitido sem restrições e de maneira clara e lúdica para que estas possam assimilar com faci- lidade e, por que não, levar este conhecimento por toda sua vida.}

Essa tendência - aliar os aspectos educacionais e afetivos - leva a uma aprendizagem mais significativa e evidencia a natureza do conhecimento científico como fruto do raciocínio lógico e tam-

\footnotetext{
1 Material didático é aquele que apresenta conteúdo selecionado de uma área, de acordo com uma proposta pedagógica específica.

2 Material paradidático auxilia o processo de aprendizagem, aprofundando ou ampliando um tema. Geralmente utiliza aspectos mais lúdicos.
} 
bém dos valores construídos durante a formação escolar (Seniciato e Cavassan 2004), contribuindo para a AC (Lorenzetti e Delizoicov 2001).

Desta forma, os jogos pedagógicos empregados nas oficinas didáticas, se mostram como uma ferramenta importante para o ensino das Geociências, já que, na visão de Neves, Campos e Simões (2008), não basta somente abordar o aspecto teórico do ensino, mas também é necessário criar alternativas para instigar os alunos a aprender de forma divertida, para não esquecer o tema estudado e, ainda, facilitar a reflexão e discussão dos conteúdos apresentados em sala de aula. Essa associação entre o uso de jogos e oficinas didáticas com temas de Geociências é algo ainda pouco explorado, uma vez que, são poucos os relatos educacionais do uso de jogos em Geociências, como visto em Lopes e Carneiro (2009).

De fato, os jogos educativos instigam o aluno, o motivam e despertam sua curiosidade, proporcionando uma forma de aprender de maneira lúdica, prazerosa, bem diferente dos resultados de uma aprendizagem sob pressão (Kishimoto 1998).As Geociências, por vezes, necessitam de estratégias para auxiliar a construção de conceitos abstratos que se tornam difíceis de explicar somente através de discursos, como a noção do tempo geológico. Nesse quesito Campos, Bortoloto e Felício (2003), mostram que, ao aliar os aspectos lúdicos aos cognitivos, o jogo torna-se uma importante estratégia para o ensino e a aprendizagem de conceitos abstratos e complexos, favorecendo a motivação interna, o raciocínio, a argumentação, a interação entre alunos e entre professores e alunos.

No caso do ensino das Geociências, o uso de atividades lúdicas, nas suas mais variadas formas, deve ser amplamente incorporado como uma das estratégias para a promoção da AC. Assim, as atividades, adaptadas à realidade e às condições de cada um dos envolvidos, não apresentarão uma série de conceitos a serem memorizados, mas sim deverão instigar os alunos a construírem o conhecimento integrado sobre a disciplina, já que o conhecimento fragmentado, para Carneiro, Toledo e Almeida (2004) e Guimarães (2004) ainda é uma das principais dificuldades a ser superada pelo ensino das Geociências. As diferentes estratégias trabalhadas nas oficinas permitem associar conhecimentos do cotidiano aos conhecimentos científicos, a fim de contribuir de forma efetiva no entendimento dos conteúdos. Mediante essas considerações, neste artigo, defendemos a utilização das Geociências, em especial da Paleontologia, como ferramenta para a promoção da AC (de acordo com conceito defendido por Sasseron e Carvalho 2008) no Ensino Fundamental apresentando e discutindo uma experiência a partir de oficinas didáticas.

\section{Proposta de Ensino}

\section{Contextualização e proposta de ensino}

A construção de uma usina hidrelétrica interfere, mesmo que indiretamente, nos bens paleontológicos. Em virtude disso, é essencial um programa de proteção, monitoramento e resgate dos fósseis, conforme estabelecido nas diretrizes do Estudo de Impacto Ambiental-EIA. Com a construção dos empreendimentos hidrelétricos no rio Madeira, houve a necessidade da execução de um programa de preservação dos bens paleontológicos ${ }^{3}$, bem como de um programa de divulgação e educação paleontológica ${ }^{4}$ associado ao município de Porto Velho, Rondônia.

$\mathrm{Na}$ cidade de Porto Velho, a divulgação das Geociências é praticamente inexistente, o que é semelhante ao cenário nacional, segundo Eerola (1994). Dada à ausência de trabalhos na temática de educação em Paleontologia na região, buscou-se elaborar uma proposta que pudesse contribuir para a melhoria do ensino de Paleontologia no ambiente escolar, afinal, mesmo com o crescente aumento de abordagens para facilitar o entendimento das Geociências no Ensino Fundamental (Mello, Mello e Torello 2005, Neves, Campos e Simões 2008, Perez et al. 2011), em uma análise geral, essas ações são ainda pontuais.

Assim, a equipe desenvolveu uma série de nove oficinas didáticas tratando da ciência da Paleontologia e os temas a ela relacionados, voltadas para estudantes com idade entre 10 e 13 anos, pois de acordo com os PCN (Brasil 1998), é nessa faixa etária que começam a ser discutidos temas ligados as Geociências, uma vez que a criança passa a ter noções de tempo, causalidade e conservação, conceitos importantes para a compreensão dos fenômenos geocientíficos (Ferracioli 1999).

Cada uma das oficinas tem duração de 90 minutos e está organizada em três momentos dis-

3 Programa de Preservação do Patrimônio Paleontológico - UHE Santo Antônio, executado pela Scientia Consultoria Científica Ltda., entre os anos de 2009 e 2011.

4 Sub-programa de Educação em Paleontologia, executado pela mesma empresa. 
tintos, trabalhados por meio de diversas atividades lúdicas, principalmente jogos educativos. O primeiro momento apresenta o tema, possibilitando discutir com os participantes suas noções prévias, ao mesmo tempo em que introduz novos dados nessa discussão; o segundo momento organiza e reforça as novas informações, permitindo aos estudantes o contato mais aprofundado com o tema proposto; o terceiro momento, por sua vez, possibilita a aplicação do conhecimento em situações lúdicas diversas, incentivando a capacidade de trabalhar com as novas informações, utilizando o raciocínio lógico e a criatividade, auxiliando na AC.

Embora as nove oficinas educativas elaboradas sejam independentes entre si, juntas, elas complementam-se, oferecendo uma visão ampla sobre a Paleontologia, com os principais aspectos ligados direta ou indiretamente a esta ciência. A Paleontologia como tema de trabalho permite a abordagem de disciplinas científicas da área de Ciências Naturais de modo interrelacionado. Ao abranger conhecimentos biológicos (como evolução, por exemplo), físicos e químicos (como fossilização), sociais e culturais (como a importância da divulgação científica) a partir de uma situação significativa na vivência dos estudantes (a construção da UHE), integra-se vários eixos e temas transversais, buscando-se alcançar o que é sugerido pelos PCN. De modo conjunto, as oficinas, organizadas em sequências didáticas, obedecem a uma ordem hierárquica, abordando os seguintes temas:

1. Noções de Paleontologia: além de permitir o contato dos alunos com os fósseis, tem o objetivo de apresentar a Paleontologia para os estudantes, discutindo os principais conceitos envolvidos com essa ciência, tais como fósseis, escavação paleontológica, paleontólogo, animais extintos, entre outros.

2. Como se Formam os Fósseis: procura propiciar a compreensão dos eventos envolvidos no processo de formação de restos e vestígios fósseis.

3. O Trabalho do Paleontólogo: busca oferecer aos estudantes contato com os principais métodos utilizados pelos paleontólogos para desvendarem o passado biológico do planeta Terra, oportunizando tanto o contato com o trabalho de campo quanto com o trabalho de laboratório.

4. O Tempo Geológico: objetiva propiciar a compreensão da noção de tempo profundo ${ }^{5}$,

5 Os PCN recomendam que se amplie a noção de tempo cíclico para ampliando o conceito de tempo cíclico para a ideia de tempo não-cíclico, que comporta conhecimentos de evolução, de passado, de registro, de memória e de presente, de mudanças essenciais e irreversíveis (Brasil 1998), importantes para o entendimento da história biológica e geológica do planeta Terra.

5. Evolução Biológica: aborda a origem da vida na Terra e a evolução por meio da seleção natural, mostrando a importância dos fósseis para a compreensão desse processo.

6. As Transformações do Planeta Terra: tem como objetivo mostrar aos estudantes as constantes transformações pelas quais o planeta passou ao longo de sua história geológica, auxiliando, assim, na compreensão dos processos dinâmicos, tão importantes para a Geologia e a Biologia. Além disso, essa oficina trabalha ainda com o desenvolvimento do pensamento científico através da análise de dados, oferecendo aos alunos a oportunidade de avaliarem criticamente as informações disponíveis para a proposição de uma hipótese.

7. Os Dinossauros: busca discutir com os estudantes aspectos sobre a biologia desse fascinante grupo de animais extintos.

8. Megafauna Pleistocênica: objetiva propiciar a compreensão do conhecimento científico existente sobre esses animais e incentivar o interesse pelo grupo, ricamente representado pelos fósseis encontrados em Rondônia.

9. Extinções: procura mostrar aos estudantes a existência de um equilíbrio natural entre o surgimento e o desaparecimento de espécies ao longo da história do planeta, e como esse equilíbrio pode ser afetado por grandes extinções em massa, causadas por eventos naturais ou, mais recentemente, pelo Homem.

Os dinossauros foram contemplados com uma oficina específica por constituírem um grupo fóssil que apresenta um apelo especial com estudantes da faixa etária atendida. De maneira geral, o grande público demonstra interesse por fósseis, especialmente, pelos dinossauros (Eerola 1994). Já a Megafauna, proveniente de depósitos da Formação Rio Madeirado Pleistoceno Superior,

tempo não cíclico de modo a permitir que os estudantes compreendam transformações geológicas que ocorreram em tempos distantes no planeta Terra. 0 documento recomenda, inclusive, que se utilizem os fósseis para facilitar essa compreensão (págs 40 e 41 "Terra e Universo"). 
é apresentada de forma detalhada em uma oficina específica devido ao fato de este grupo constituir a maior parte do registro fóssil da região de Porto Velho e municípios próximos, além de ser alvo dos resgates da área atingida pela construção da usina. Os demais grupos fósseis, tais como invertebrados e plantas, por exemplo, foram apresentados ao longo de outras oficinas.

No que tange ao material didático utilizado nas oficinas, estes foram originalmente elaborados pela equipe do subprograma de Educação em Paleontologia ou adaptado de atividades disponíveis em sites da internet e livros.

\section{Avaliação}

Com o objetivo de avaliar a efetividade do aprendizado dos estudantes a partir das oficinas didáticas elaboradas, a sequência completa de oficinas foi aplicada através de um projeto direcionado às classes de $5^{\circ}$ ano da Escola Estadual de Ensino Fundamental Bom Jesus, localizada na Zona Centro-Norte de Porto Velho, Rondônia. Após a aprovação do projeto junto à coordenação pedagógica da instituição, as oficinas foram aplicadas separadamente, com as turmas dos $5^{\circ}$ anos A e B (em um total de 62 alunos), com intervalo de uma semana entre cada uma das oficinas. $\mathrm{O} 5^{\circ}$ ano do Ensino Fundamental foi escolhido, pois, nessa turma, a idade média dos estudantes é de 10 anos, base da faixa etária atendida pelo conjunto de oficinas. Como forma de auxiliar na estimativa do aprendizado adquirido ao longo do projeto, foram realizadas uma avaliação prévia (uma semana antes do início das oficinas para a turma do $5^{\circ}$ ano $\mathrm{A} \mathrm{e}$ duas semanas antes do início das oficinas para o $5^{\circ}$ ano B) e uma avaliação final dos conhecimentos dos alunos sobre o tema (duas semanas após a aplicação de todas as oficinas). Ambas as avaliações consistiam em uma sequência de figuras que deveriam ser descritas pelos alunos de maneira livre, da forma como eles julgassem mais adequado (Fig. 1).As descrições feitas por cada aluno, individualmente, antes e depois do projeto, foram então comparadas em análise qualitativa, que considerou a elaboração das descrições, e quantitativa em relação ao uso de termos específicos apresentados e discutidos no decorrer das oficinas. Com o objetivo de identificar se o desenvolvimento do projeto colaborou para o processo de AC dos estudantes, a presença dos Eixos Estruturantes da Alfabetização Científica, propostos por Sasseron e Carvalho (2008, 2011), foi analisada nos textos elaborados pelos alunos. De acordo com as autoras, esses eixos são capazes de fornecer bases suficientes e necessárias de serem consideradas em projetos que visem a $\mathrm{AC}$ e consistem em: 1) compreensão básica de termos, conhecimentos e conceitos científicos fundamentais; 2) compreensão da natureza da ciência e dos fatores éticos e políticos que circulam sua prática; 3 ) entendimento das relações existentes entre ciência, tecnologia, sociedade e meio ambiente.

Vale enfatizar aqui que vai além do escopo deste trabalho a análise particular de cada oficina e de cada uma das atividades desenvolvidas, as quais deverão ser apresentadas em trabalhos futuros.

\section{Resultados e Discussão}

No total, 48 alunos, das duas turmas, realizaram as duas avaliações (antes e depois do projeto), quatro alunos realizaram apenas a avaliação posterior e 10 alunos realizaram apenas a avaliação prévia. Para fins de estimativa do aprendizado, as avaliações que foram realizadas pelos estudantes apenas antes do projeto foram descartadas. Entre os demais 52 estudantes, dois não comporão a análise, pois suas respostas não se mostraram de acordo com a proposta da avaliação. Dessa forma, um total de 50 alunos foi avaliado quanto ao seu aprendizado por meio das oficinas didáticas e os resultados obtidos serão apresentados sem considerar diferenças intrínsecas entre as turmas. Os nomes dos estudantes, aqui apresentados, são fictícios, de modo a manter preservada a identidade de cada um.

Em relação à utilização de termos específicos para a descrição das figuras, foi analisado o emprego de "preguiça-gigante" para descrever o animal presente; "fóssil"/"fósseis" e "paleontólogo(s)". Nas avaliações prévias, apenas um estudante (2\%) descreveu o animal como uma "preguiça-gigante", enquanto esse número passou para 35 (70\%) na avaliação realizada ao término do projeto. Vale notar que $\mathrm{o}$ aspecto analisado aqui foi a capacidade dos alunos relacionarem as imagens com uma reconstrução do passado, realizada por meio do estudo dos fósseis. Desse modo, a percepção de que se tratava de um animal que morreu há muito tempo atrás era considerada mais importante do que o reconhecimento do animal em si. Nesse sentido, a identificação do animal como "dinossauro", feita por dois alunos (4\%), ou apenas como "um animal" (feita por outros dois alunos) também indica o aumento da compreensão deles entre a realização das duas avaliações. $\mathrm{Na}$ ava- 


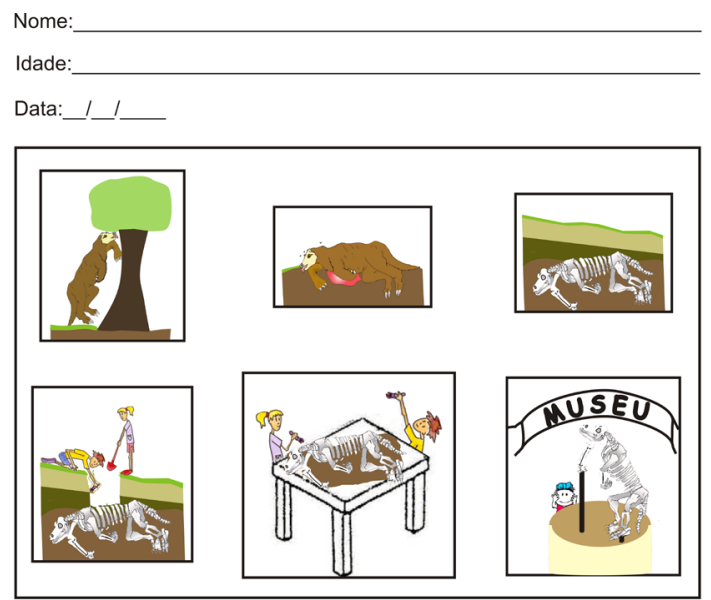

Analisando as figuras acima, descreva tudo o que você vê e acha importante de ser notado. Não há certo e errado! Apenas descreva da forma que você souber fazer.

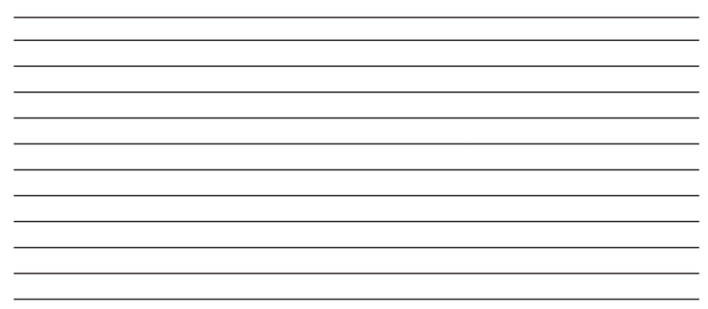

Figura 1. Avaliação de conhecimentos, aplicada aos estudantes antes e após a realização das oficinas didáticas.

liação prévia, a identificação mais comum do animal foi "urso" (72\%). Embora existam espécies extintas de urso, o desconhecimento dos alunos sobre a Paleontologia antes da realização do projeto, indicada por outros aspectos presentes nas avaliações prévias, sugere que os estudantes realmente não haviam sido capazes de relacionar o animal presente nas figuras com espécies fósseis. Seguindo a sugestão de Lemke (1997), a comparação entre as avaliações prévia e posterior foi realizada atentando para o conhecimento que os alunos possuíam, de modo a compreender os significados já atribuídos a determinadas palavras e conceitos, tais como "fóssil", "preguiça-gigante" e "paleontólogo(s)".

O termo "fóssil", que não havia sido utilizado nenhuma vez nas avaliações prévias, apareceu em 16 avaliações finais (32\%); enquanto "paleontólogo(s)", utilizado somente uma vez (2\%) antes do desenvolvimento do projeto, figurou em $26(52 \%)$ avaliações posteriores. Dessa forma, o emprego dos termos específicos de maneira correta indica que os alunos compreenderam seu significado, sendo capazes de enriquecer a descrição das imagens, conferindo-lhe maior exatidão científica, adequando-se, portanto, ao primeiro Eixo Estru- turante da AC (compreensão básica de termos, conhecimentos e conceitos científicos fundamentais) proposto por Sasseron e Carvalho $(2008,2011)$.

Vale notar, porém, que, embora o significado dos termos analisados tenha sido compreendido por uma parcela significativa dos estudantes, a avaliação final indicou que a grafia dessas palavras ainda consiste em um desafio para os alunos participantes do projeto. O termo "fóssil" foi encontrado grafado de maneiras tão díspares como "fosseu", "fosse", "foceis" e "forcio". Já "preguiça-gigante" era comumente grafada com "s" ("preguisa-gigante") e "paleontólogo" nunca se apresentava acentuada. Apesar dessas dificuldades, no entanto, a aplicação correta dos termos nos textos elaborados reforça a tese defendida por Lorenzetti e Delizoicov (2001) de que não é necessário que a criança saiba ler e escrever para iniciar sua alfabetização científica e que, além disso, o ensino de ciência pode se constituir num potente aliado para o desenvolvimento da leitura e da escrita, uma vez que contribuí para atribuir sentidos e significados às palavras e aos discursos.

A análise qualitativa realizada indicou um aumento na compreensão das etapas presentes para a reconstrução do passado, sendo comum, nas avaliações finais, a percepção da necessidade de preparação do fóssil e análise taxonômica $\left(5^{\circ}\right.$ quadrinho da avaliação) antes de sua musealização $\left(6^{\circ}\right.$ quadrinho). Antes do projeto, muitos estudantes pulavam essa passagem ou descreviam-na apenas como "estudaram o esqueleto" ou "colocaram na mesa" enquanto após o projeto, podemos encontrá-la de formas tão elaboradas como as seguintes:

“...escavaro lavaro o foceis eles viraram para o laboratorio para descobrir do que era os foceis montaru e levarau para o museu."

(Avaliação final do João)

“...e eles estão limpando e depois eles foram ao museu e colaram os ossos pecinha por pecinha."

(Avaliação final do Ricardo)

A compreensão mais elaborada das etapas envolvidas nas reconstruções paleontológicas indica, por sua vez, uma melhor compreensão da ciência, realizada de acordo com métodos estabelecidos para cada área específica do conhecimento. A análise das avaliações prévias e posteriores demonstra uma mudança no entendimento do 
conhecimento desde uma noção de algo pronto e imutável, para uma visão do conhecimento como fruto de um processo. Essa mudança é indicada pela pouca importância atribuída às passagens intermediárias, nas avaliações prévias, para a descrição mais detalhada dessas passagens, nas avaliações finais. A compreensão da ciência e de sua prática como atividade humana voltada à produção de conhecimento compreende o segundo Eixo Estruturante da AC, proposto por Sasseron e Carvalho (2008, 2011).

A percepção do processo de morte do animal também apresentou alterações entre as visões pré- e pós-participação no projeto. A morte da preguiça-gigante é atribuída pela maioria dos estudantes, em ambas as avaliações, à queda da árvore ou a ingestão de alimento contaminado, no entanto, visões novas, que incluem o processo gradual de extinção das espécies devido à mudança ambiental, estiveram presentes nas avaliações finais, como mostram os exemplos a seguir:

“...todas as coisas que ele come acabou e ele morreu."

(Avaliação final da Alice)

"...vai passando os anos o animal fica com fome porque os alimentos acabou e assim ele morre."

(Avaliação final do Daniel)

O processo de soterramento e fossilização, por sua vez, também pressupunha a compreensão da noção de grandes escalas de tempo, necessárias para a transformação da matéria orgânica em mineral. Essa noção, no entanto, ainda que tenha sido trabalhada durante o desenvolvimento do projeto (Oficina 4 - O Tempo Geológico), mostrou-se bastante complexa para os participantes, que não foram capazes de descrever com precisão o tempo transcorrido em cada etapa do processo, desde a morte do animal até a descoberta do fóssil pelos paleontólogos ( $2^{\circ}$ a $4^{\circ}$ quadrinho da avaliação).

“...a terra subterou e só ficou os ossos debaxo da terra a 500.000 .000 de anos..."

(Avaliação final do Pedro)

“...e morreu a terra cobriu ela e ela ficou enterrada. Depois de anos e anos os paleontologos acharam ele..."

(Avaliação final da Isabela)
A grande dimensão do tempo geológico, tão aquém do tempo de vida médio de um ser humano, torna a compreensão deste conceito uma tarefa complexa (Bonito et al. 2010). No caso específico do processo de soterramento e fossilização, embora os alunos tenham compreendido que um grande período temporal é necessário, a magnitude desse intervalo ainda mostra-se de difícil compreensão. Por outro lado, em sua maioria, os alunos foram capazes de localizar o lugar deste intervalo de tempo entre as etapas do processo, descrevendo-o corretamente após o evento de soterramento, como ilustrado pelos exemplos acima. Esses resultados estão de acordo com aqueles encontrados por Perez et al.(2011), que, ao analisar mais detalhadamente a eficácia da utilização do Túnel do Tempo Geológico como ferramenta didática auxiliar no ensino do conceito de tempo geológico (Oficina 4-O tempo geológico), observaram que os alunos conseguiram localizar corretamente uma sequência de eventos ao longo da história do planeta Terra, porém, apresentaram dificuldades com as magnitudes temporais, bem como com marcações relativas da passagem do tempo.

Já a importância do soterramento para o processo de fossilização da matéria orgânica parece ter sido compreendida pelos estudantes, tendo sido repetidamente descrita nas avaliações realizadas após o desenvolvimento do projeto, em contraposição às avaliações prévias, como pode ser visto nas passagens selecionadas abaixo:

“...morreu e ficol só o oso..."

“...morreu viro um esqueleto ficol enterrado e virol um fosseu..."

(Respectivamente, avaliações prévia e final do Renato)

“...ele passar pelo tempo da decomposição fica só os ossos e eu acho que a uns 10 anos á frente uma menina e um garoto desenterram ele...”

“...cai morre a terra vai cubrindo e prerserva os ossos,..."

(Respectivamente, avaliações prévia e final do Marcos)

Por outro lado, o processo pelo qual o animal é soterrado, por meio da ação das forças naturais que transportam o sedimento (por exemplo, vento 
e água), mostrou-se difícil de ser elaborado pelos estudantes, que não foram capazes de descrevê-lo, claramente, como um evento fortuito, e não intencional e dirigido. Abaixo estão duas passagens que ilustram essa dificuldade:

"...e as camadas de terra afundaram ele..."

(Avaliação final do Artur)

“...e depois fica o esqueleto e vai para de baixo da terra..."

(Avaliação final da Paula)

Embora a oficina 2 (Como se formam os fósseis) trabalhe especificamente o processo de fossilização da matéria orgânica, os processos de erosão do solo e transporte de sedimentos não são diretamente abordados e discutidos. Dessa forma, as confusões conceituais analisadas acima evidenciam a tentativa dos estudantes de acomodarem seus conhecimentos prévios ao novo conhecimento obtido durante a participação no projeto. O bom ensino é o que relaciona os conceitos científicos (construídos em situação formal de aprendizagem) aos conceitos espontâneos (construídos em situações cotidianas, não-sistematizadas) e auxilia o educando a internalizá-los, em um movimento espiralado, no qual vai aprendendo novos conceitos e, por conseguinte, se desenvolvendo (Araújo, Araújo e Scheffer 2009).

Por fim, outro aspecto importante que passou a figurar nas avaliações após a realização do projeto foi a noção da importância da divulgação do conhecimento científico para a sociedade, evidenciada pela maior elaboração na descrição referente à musealização dos fósseis ( $6^{\circ}$ quadrinho). O entendimento das relações existentes entre ciência, tecnologia, sociedade e meio-ambiente, para o qual as ações de educação e divulgação são fundamentais, é considerado por Sasseron e Carvalho $(2008,2011)$ como o terceiro Eixo Estruturante da AC. Nas passagens abaixo, selecionamos dois exemplos do incremento na compreensão dessa ação, comparando as avaliações prévia e final:

“...e levaram para o museu."

"Levaram para o muzeu e muitas pessoas ficaram encantadas."

(Respectivamente, avaliações prévia e final do Marcelo) “...achar o os ossos do urso e levaro para o museu."

“...e levam os ossos dele para o museu para as pessoas descobrirem que tipo de animais viveram durante o tempo que não existiamos."

(Respectivamente, avaliações prévia e final da Camila)

Além disso, o contexto econômico local no qual se inseriu a realização do projeto (a construção da usina) permitiu aos estudantes entenderem o trabalho dos cientistas (no caso, especificamente dos paleontólogos) dentro de uma dimensão social e ambiental, dada a necessidade de tornar conhecida a riqueza fossilífera regional, indiretamente afetada pelo empreendimento. A abordagem de conteúdos intimamente relacionados ao mundo cotidiano dos alunos, aos problemas sociais, políticos e econômicos que norteiam os rumos da sociedade em que está inserido, auxilia-os a fazer conexões críticas entre os conhecimentos sistematizados pela escola com os assuntos relacionados à suas vidas (Lorenzetti e Delizoicov 2001, Penha, Carvalho e Viana 2009). Vale notar ainda que muitos familiares dos alunos participantes tinham alguma relação de trabalho (direta ou indireta) com o empreendimento, o que acarretou em uma enriquecedora troca de conhecimento não só sobre Ciências Naturais, mas também sobre Sociedade e Meio Ambiente, entre a casa e a escola.

A ferramenta avaliativa utilizada neste trabalho permitia aos estudantes escreverem livremente, apresentando suas ideias sobre a sequência de figuras oferecidas da maneira como julgasse mais adequada. A escolha dessa forma de avaliação tem a vantagem de deixar os alunos a vontade para trabalhar seu próprio conhecimento, sem pressões de respostas certas ou erradas. A maior ou menor articulação na construção dos textos, apresentando as novas noções discutidas em sala de aula, realça a construção pessoal do conhecimento, exercendo a função de organizar o conhecimento já existente com as novas aquisições, após as discussões em sala de aula. Ao escrever, o aluno conscientiza-se acerca do que sabe e do que não sabe e estabelece novas relações, com outras ideias e com suas próprias observações (Rivard e Straw 2000).

\section{Conclusão}

Apesar de algumas confusões conceituais, o resultado final alcançado pelo projeto foi considera- 
do satisfatório, uma vez que introduziu no universo dos alunos conhecimentos científicos com os quais eles são capazes de trabalhar, ainda que de maneira incipiente. A utilização de ferramentas lúdico-pedagógicas, que estimularam a curiosidade, a perspicácia e a sagacidade próprias das crianças dessa faixa etária (Sasseron e Carvalho 2008), auxiliaram os estudantes a compreenderem que o conhecimento paleontológico é resultado de um processo extenso de estudos de campo e de laboratório para reconstruir os passos de um processo ainda mais longo, iniciado há milhares, milhões ou bilhões de anos no passado. A medida que os alunos avançarem no decorrer da vida acadêmica, o aprendizado adquirido sobre o modo de se fazer ciência deverá ser continuamente acessado e, consequentemente, deverá consolidar-se, dando a eles uma perspectiva crítica e mais elaborada do conhecimento científico atual.

Adicionalmente, os resultados obtidos indicaram que o processo de AC pode e deve ser iniciado desde os primeiros anos do Ensino Fundamental, constituindo-se um aliado para que o aluno possa ler e compreender seu universo (Lorenzetti e Delizoicov 2001) e ainda permitir que o aluno entenda que a ciência está em seu cotidiano e não apenas na sala de aula. As Geociências colaboram e muito nesse processo, por meio das diferentes formas de abordagem. A interdisciplinaridade e a divulgação da mídia fazem das Geociências, em especial da Paleontologia, um campo do saber fundamental no processo de AC.

\section{Agradecimentos}

O presente trabalho foi realizado com apoio financeiro da Concessionária Santo Antônio Energia S.A. e com apoio logístico da Scientia Consultoria Científica Ltda., ambos no âmbito da execução do Programa de Preservação do Patrimônio Paleontológico - UHE Santo Antônio.

As autoras agradecem à coordenação pedagógica e às professoras dos $5^{\circ}$ anos da Escola Estadual de Ensino Fundamental Bom Jesus pelo apoio à iniciativa e pelo apoio educacional e logístico durante o desenvolvimento do projeto.As autoras agradecem ainda aos pesquisadores Tirla Tavares dos Santos, Marcos César Bissaro Júnior, Ednair Rodrigues do Nascimento e Michelle MayumiTizuka pela parceria durante a execução do programa, bem como à pesquisadora Eneida Malerbi pelas valiosas contribuições críticas que tanto colaboraram na construção deste texto.

\section{Referências}

Araújo V.C., Araújo R.C.B.F., Scheffer A.M.M. 2009. Discutindo aprendizagem e desenvolvimento da criança à luz do referencial histórico-cultural. Vertentes, 33:77-88. URL: < http://www.ufsj.edu.br/ portal2-repositorio/File/vertentes/viviam_e_outras.pdf > Accesso: 04.01.2013.

Bacci D., Oliveira L., Pommer C. 2009. Contribuição da abordagem geocientífica no Ensino Fundamental: Tempo Geológico, origem do petróleo e mudanças ambientais. Enseñanza de las Ciencias, Número Extra VIII Congreso Internacional sobre Investigación em Didáctica de las Ciencias: 3459-3463.

Bonito J., Marques L., Morgado M., Rebelo D., Medina J., McDade G.M., Martins L. 2010. A importância do Tempo Geológico percebida por alunos de 12-13 anos: um estudo realizado em escolas nas zonas centro e norte de Portugal. In: Congr. Bras. Geol., 45, Belém, 2010. Anais... Belém, SBGeo. CD-ROM.

Brasil. Ministério da Educação. Secretaria de Educação Fundamental. 1998. Parâmetros Curriculares Nacionais: Ciências Naturais - Terceiro e Quarto Ciclos do Ensino Fundamental. Brasília, MEC/SEF.

Campos L.M.L., Bortoloto T.M., Felício A.K.C. 2003. A produção de jogos didáticos para o ensino de ciências e biologia: uma proposta para favorecer a aprendizagem. Cadernos dos Núcleos de Ensino, 47-60. URL: http://www.unesp.br/prograd/ PDFNE2002/aproducaodejogos.pdf. Acesso 15.04.2013.

Carneiro C.D.R., Toledo M.C.M., Almeida F.F.M. 2004. Dez motivos para a inclusão de temas de Geologia na Educação Básica. Rev. Bras. Geoc., 34(4):553-560.

Chagas I. 2000. Literacia científica. O grande desafio para a escola. In Encontro nacional de investigação e formação, globalização e desenvolvimento profissional do professor, 1. Actas... Lisboa, 2000. URL: http://www.eselx.ipl.pt/Iencontro/Actas/ textos/Paineis Chagas.htm. Acesso 07.11.2012.

Eerola T. 1994. Problemas da divulgação e popularização de Geociências no Brasil. Rev. Bras. Geoc., 24(3):160-163.

Ferracioli L. 1999. Aprendizagem, desenvolvimento e conhecimento na obra de Jean Piaget: uma análise do processo de ensino-aprendizagem em Ciências. Rev. Bras. Est. Pedag., 80(194):5-18.

Furman M. 2009. O ensino de ciências no Ensino Fundamental: colocando as pedras fundacionais do pensamento científico. São Paulo: Sangari Brasil. 19p.

Guimarães E.M. 2004. A contribuição da Geologia na construção de um padrão de referência do mundo físico na educação básica. Rev. Bras. Geoc., 34(1):87-94. 
Hurd P.H. 1958. Science Literacy: its meaning for american schools. Educational Leadership. 16:13-16.

Kishimoto T.M. 1998. Jogos infantis: o jogo, a criança e a educação. Petrópolis: Vozes. 127p.

Lemke J.L. 1997. Aprender a hablar ciencia. Barcelona: Paidós. 272p.

Lira M., Teixeira F.M. 2011. Alfabetização científica e argumentação escrita: proposições reflexivas. In VIII Encontro Nacional de Pesquisa em Educação em Ciências e I Congreso Iberoamericano de Investigación en Enseñanza de Las Ciencias. Campinas, 2001. URL: http://adaltech.com.br/ testes/abrapec/resumos/R1387-1.pdf.. Acesso 06.11.2012.

Lopes O.R., Carneiro C.D.R. 2009. O jogo "Ciclo das Rochas” para ensino de Geociências. Rev. Bras. Geoc., 39(1):30-41.

Lorenzetti L., Delizoicov D. 2001. Alfabetização científica no contexto das séries iniciais. Ensaio: Pesq. Educ. Ciênc., 3(1):1-17. URL: http://redalyc. uaemex.mx/redalyc/pdf/1295/129517973004.pdf. Acesso 17.09.2012.

Mello F.T., Mello L.H.C., Torello M.B.F. 2005. A Paleontologia na Educação Infantil: alfabetizando e construindo o conhecimento. Ciência \& Educação, 11(3):395-410.

Mesquita M.J.M., Picanço J.L., Besser M.L., Ribeiro J.C., Dmeterko H., Silva A.L. da, Cruz G.M. da, Acordes F.A., Ribeiro P.R., Hamerscmidt T., Morais J.E.F., Berton F., Mattos R.F. de, Schemiko D.C.B 2011. A experiência da oficina "Do mito à natureza: educar o olhar para as Ciências da Terra" no Festival de Inverno de Antonina (PR). Terrae Didatica, 7(2):75-85. URL:http://www.ige.unicamp.br/terraedidatica/v7_2/pdf72/Td72-color-4. pdf. Acesso 7.12.2012.

Neves J.P., Campos L.M.L., Simões M.G. 2008. Jogos como recurso didático para o ensino de conceitos paleontológicos básicos aos estudantes do Ensino
Fundamental.Terr@Plural, 2(1):103-114.

Penha S.P., Carvalho A.M.P., Vianna D.M. 2009. A utilização de atividades investigativas em uma proposta de enculturação científica: novos indicadores para análise do processo. In VII Encontro Nacional de Pesquisa em Educação em Ciências. Anais... Florianópolis, 2009. URL: http://posgrad. fae.ufmg.br/posgrad/viienpec/pdfs/612.pdf. Acesso 23.11 .2012 .

Perez C.P., Rodrigues M.F., Santos T.T., Andrade L.C. 2011. O túnel do tempo geológico: ferramenta didática para o ensino de geociências no ensino fundamental e médio. In Carvalho I.S., Srivastava N.K., Strohschoen Jr. O., Lana C.C. eds. 2011. Paleontologia: Cenários da Vida. Rio de Janeiro: Ed. Interciência. p. 709-718. (Vol. 4).

Piranha J.M., Carneiro C.D.R. 2009. O ensino de Geologia como instrumento formador de uma cultura de sustentabilidade. Rev. Bras. Geoc., 39(1):129-137.

Rivard L.P., Straw S.B. 2000. The effect of talk and writing on learning science: an exploratory study. Science Education, 84:566-593.

Sasseron L.H.,Carvalho A.M.P. 2008. Almejando a alfabetização científica no ensino fundamental: a proposição e a procura de indicadores do processo. Investigações em ensino de Ciências, 13(3):333-352. URL: http:/www.cienciamao.if.usp.br/dados/ ard/_almejandoaalfabetizacaoc.url.pdf. Acesso 07.09.2012.

Sasseron L.H.,Carvalho A.M.P. 2011. Construindo argumentação na sala de aula: a presença do ciclo qrgumentativo, os indicadores de Alfabetização Científica e o Padrão de Toulmin. Ciência \& Educação, 17(1):97-114.

Seniciato T., Cavassan O. 2004. Aulas de campo em abientes naturais e aprendizagem em Ciências um estudo com alunos do Ensino Fundamental. Ciência E Educação, 10(1):133-147.

Resumo : As Geociências são essenciais para o entendimento do mundo físico, embora ainda sejam pouco utilizadas para promover a Alfabetização Científica (AC) no Ensino Fundamental (EF) no Brasil. Este estudo investiga a efetividade de oficinas didáticas para 0 ensino de Geociências, além de examinar sua contribuição no processo de AC de estudantes do EF. Cada uma das nove oficinas foi aplicada a duas turmas de $5 .{ }^{\circ}$ ano, utilizando diferentes ferramentas pedagógicas e abordando um tema específico das Geociências, com ênfase na Paleontologia. Como forma de avaliação foram realizados testes de conhecimento antes e após o desenvolvimento do projeto, comparando-os em análises qualitativa e quantitativa. A partir dos resultados, detectou-se: 1) compreensão básica de termos específicos; 2) compreensão das etapas necessárias para a identificação e 0 estudo dos fósseis; 3) entendimento das etapas necessárias ao processo de fossilização; 4) compreensão da natureza da ciência e do fazer científico; 5) reconhecimento da importância da divulgação do conhecimento científico para a sociedade. Os resultados indicaram a viabilidade do início do processo de AC nos primeiros anos da vida escolar e a relevância das Geociências como forma de envolver os estudantes com temas científicos.

PALAVRAS-CHAVE - Geociências, Paleontologia, oficinas, jogos didáticos, Alfabetização Científica. 